\title{
Occupational risk factors of lung cancer: a hospital based case-control study
}

Jos H J Droste, Joost J Weyler, Jan P Van Meerbeeck, Paul A Vermeire, Marc P van Sprundel

\begin{abstract}
Objectives-To investigate the relation between lung cancer and exposure to occupational carcinogens in a highly industrialised region in western Europe.

Methods-In a case-control study 478 cases and 536 controls, recruited from 10 hospitals in the Antwerp region, were interviewed. Cases were male patients with histologically confirmed lung cancer; controls were male patients without cancer or primary lung diseases. Data were collected by questionnaires to obtain information on occupations, exposures, and smoking history. Job titles were coded with the Office of Populations, Censuses and Surveys industrial classification. Exposure was assessed by self report and by job-task exposure matrix. Exposure odds ratios were calculated with logistic regression analysis adjusted for age, smoking history, and marital and socioeconomic status.
\end{abstract}

Results-A job history in the categories manufacturing of transport equipment other than automobiles (for example, shipyard workers), transport support services (for example, dockers), and manufacturing of metal goods (for example, welders) was significantly associated with lung cancer (odds ratios (ORs) 2.3, 1.6, and 1.6 respectively). These associations were independent of smoking, education, civil, and economic status. Self reported exposure to potential carcinogens did not show significant associations with lung cancer, probably due to nondifferential misclassification. When assessed by job-task exposure matrix, exposure to molybdenum, mineral oils, and chromium were significantly associated with lung cancer. A strong association existed between smoking and lung cancer: OR of ex-smokers 4.2, OR of current smokers $14.5 v$ non-smokers. However, smoking did not confound the relation between occupational exposure and lung cancer.

Conclusions-The study has shown a significant excess risk of lung cancer among workers in manufacturing of metal goods, manufacturing of transport equipment (other than automobiles), and transport support services. Assessment of exposure to specific carcinogens resulted in significant associations of chromium, mineral oils, and molybdenum with lung cancer. This study is, to our knowledge, the first study reporting a significant association between occupational exposure to molybdenum and lung cancer. (Occup Environ Med 1999;56:322-327)

Keywords: lung cancer; occupational exposure; job task exposure matrix

For many years lung cancer has been the most common type of cancer among men in industrialised, developed countries. The incidence of lung cancer in Belgium is one of the highest in Europe. ${ }^{1}$ Many epidemiological studies on the geographical variance in occurrence of lung cancer indicates that most lung cancer incidence can be explained by external, environmental, or behavioural factors. Of these, cigarette smoking is the main risk factor. Occupational exposure to carcinogens also has a significant effect on the occurrence of lung cancer. Reported population attributable risk percentages range from 3 to $35 .^{2-8}$ In Belgium, the Antwerp area in particular is one of the most industrialised regions of north west Europe. However, no studies have been published on the associations between lung cancer and a wide range of occupations and exposures to carcinogens in Belgium.

At present, many occupations, industries, and specific chemical substances have been associated with a well established or suspected excess risk of lung cancer. ${ }^{9-12}$ These associations have often been determined by casecontrol studies. Inherent to that type of study is the difficulty in assessing exposure to potential carcinogens. As the study design is retrospective and exposures occurred in the (remote) past, data from industrial hygiene records or environmental measurements are usually not available. The most simple and inexpensive method consists of questioning the subject about occupational contacts with chemical substances. However, this approach is the most inaccurate, because it is very sensitive to misclassification. Another method often used is the assessment of potential exposure through evaluation of occupational circumstances by experts in occupational hygiene. This approach is labour intensive and therefore costly. As a compromise between these methods job exposure matrices (JEM) are being used to link occupations to potential exposures. ${ }^{13}$ The advantage of this method is the opportunity to link simultaneously many occupations with many potential hazardous substances. A disadvantage of a general JEM, containing a wide and heterogeneous range of occupations, is its chance of misclassification. ${ }^{14}{ }^{15}$ A JEM identifies 
different job categories in which similar exposure occurs, but it does not identify differences in exposures within job categories. Thus, many subjects within the same job category will erroneously be assigned with the same exposures.

In the present study we examined a hospital based male population of 1014 subjects to determine the associations between well known or suspected carcinogens and lung cancer. To increase the accuracy of the exposure assessment we used information on specific job tasks derived from additional questionnaires, given to each subject with a history of employment in a job category in which exposure to carcinogens could be expected. ${ }^{16}{ }^{17}$ In the analyses adjustments were made for smoking and other potentially confounding factors.

\section{Subjects and methods}

STUDY DESIGN

The current study was designed as a hospital based case-control study. The catchment areas of the participating hospitals had to include the total Antwerp area, to ensure that no selection bias would occur on socioeconomic characteristics, occupational conditions, and potential exposures. The participating hospitals included the three major general hospitals of the area which act as regional oncology centres; most subjects were expected to originate from these hospitals. The hospitals also had to participate in the regional cancer registry (Cancer Registry, Province of Antwerp), by which it will be possible to evaluate clinical and pathological data in the future. Cases included all incident male primary lung cancer patients (ninth revision of the international classification of diseases ICD-9, code 162) who were referred to one of the 10 participating hospitals in the greater Antwerp area. Diagnosis had to be confirmed histologically. Controls were recruited from all eligible male patients, admitted in the corresponding week into other departments of the same hospitals, mainly from cardiovascular surgery wards. To minimise the chance of controls having diseases that may be related to the exposures under study, patients with any type of cancer or with any primary lung disease were excluded from the control group. Cases as well as controls had to have been living or working in the region since 1969.

DATA COLLECTION

Data collection took place by personal interviews between March 1995 and November 1997. All newly included cases and controls were visited by one of three trained interviewers mainly during hospital admission or occasionally during a visit to the outpatient clinic.

Data were collected with questionnaires, adapted from those used in the study by the University of Liège. ${ }^{18}$ The main questionnaire included questions on personal data, occupations held for at least 6 months (including jobs, industries, and duration of employment), hobbies and leisure activities, exposure to 16 potential carcinogens and an extensive inquiry into the subjects' smoking history. Depending on the job history additional job specific questionnaires were given to identify job tasks with a probable exposure to the carcinogens under study. These carcinogens, identified in the scientific literature as potentially carcinogenic, ${ }^{10}{ }^{11}$ were: chromium, nickel, nickel-carbonyl, molybdenum, uranium, beryllium, arsenic, asbestos, polycyclic aromatic hydrocarbons (PAHs), mineral oils, solvents, vinylchloride, lindane and other pesticides, ionising radiation, bischloromethyl, and wood dust.

Job titles were coded according to the Office of Populations, Censuses and Surveys industrial classification for the 1981 census summary, ${ }^{19}$ which consists of nine divisions, subdivided into 62 job classes. In this study the coding level was limited to the first two digits of four digit job codes. In four job classes neither cases nor controls were present. Given the few subjects in some categories several related job classes have been aggregated into a common category - for example, agriculture + forestry + fishing - resulting in a classification system of 26 job classes.

\section{EXPOSURE ASSESSMENT}

Occupational exposure to the 16 potential carcinogens under study was assessed by self reported exposure and with a job task exposure matrix (JTEM). Self reported exposure was investigated in all subjects by questions on contact with each of the carcinogens "have you ever been exposed to ... ?". Next, to link occupations with specific exposures, additional job specific questionnaires were applied to those subjects who reported occupations in job categories in which a potential exposure was expected. For that purpose, the interviewers were provided with a checklist of occupations and industries related to these job categories. Table 1 shows a list of the job categories with potential exposure and their corresponding carcinogens. Each job specific questionnaire contained questions on specific job activities or job tasks, which were subsequently related to exposure to one or more of the potential carcinogens. The information on exposure was based on current publications on occupational hygiene, and subsequently reviewed by occupational consultants and hygienists from several industries. This resulted, by analogy to a job exposure matrix, in a job task exposure matrix with carcinogens on the $\mathrm{x}$ axis and job tasks on the $y$ axis (instead of job titles as in a JEM). Each exposure was coded dichotomously (ever or never) as well as by the cumulative duration of exposure (years).

SMOKING STATUS AND TOBACCO CONSUMPTION Smoking, determined by questionnaire, was categorised as never smoker, ex-smoker, or current smoker. Current smokers were defined as those who smoked at least one cigarette daily or one cigar weekly for a period of 1 year and who were still smoking within 1 month before the examination. Ex-smokers were all smokers who stopped smoking at least 1 month before the examination. All others were considered to be never smokers. The lifetime tobacco 
Table 1 fob categories in the 1981 OPCS industrial classification with a potential risk of lung cancer and their corresponding carcinogens, used as basis for the job task exposure matrix

\begin{tabular}{|c|c|c|}
\hline Code & fob category & Carcinogenic exposure \\
\hline 100 & Agriculture, fishing & Arsenic, lindane, solvents, PAHs \\
\hline 1200 & Coke ovens & Asbestos, PAHs \\
\hline 1400 & Mineral oil processing & Chromium, mineral oils, PAHs, molybdenum, nickel, nickel-carbonyl, solvents \\
\hline 1500 & Nuclear fuel production & Uranium, ionising radiation, beryllium, PAHs \\
\hline 2200 & Metal manufacturing & $\begin{array}{l}\text { Chromium, nickel, arsenic, mineral oils, PAHs, molybdenum, asbestos, beryllium, } \\
\text { bischloromethyl }\end{array}$ \\
\hline 2400 & Non-metallic mineral production & Chromium, nickel, PAHs, arsenic, asbestos, beryllium, molybdenum \\
\hline 2500 & Chemical industry & $\begin{array}{l}\text { Chromium, nickel, arsenic, asbestos, mineral oils, PAHs, solvents, molybdenum, } \\
\text { bischloromethylether, vinylchloride, lindane }\end{array}$ \\
\hline 3100 & Manufacture of metal goods & Chromium, mineral oils, molybdenum, arsenic, nickel, solvents \\
\hline 3200 & Mechanical engineering & Chromium, nickel, arsenic, asbestos, beryllium, molybdenum, PAHs, solvents \\
\hline 3400 & Electrical engineering & Chromium, nickel, nickel-carbonyl, PAHs, arsenic, asbestos, molybdenum, beryllium, uranium \\
\hline 3500 & Manufacture of motor vehicles & Chromium, PAHs, arsenic, asbestos, solvents \\
\hline 4300 & Textile industry & Chromium, PAHs, arsenic, asbestos, nickel \\
\hline 4400 & Manufacture of leather goods & Chromium, molybdenum, arsenic, asbestos, solvents \\
\hline 4600 & Timber or wooden furniture & Chromium, PAHs, asbestos, solvents, lindane, wooddust \\
\hline 4700 & Paper products or printing & Chromium, bischloromethylether, arsenic, asbestos, solvents \\
\hline 4900 & Other manufacturing industries & Chromium, mineral oils, PAHs, arsenic, asbestos, beryllium, nickel, solvents \\
\hline 5000 & Construction & Chromium, PAHs, asbestos, nickel, solvents \\
\hline 6700 & Repair vehicles or goods & Chromium, PAHs, mineral oils, asbestos \\
\hline 7100 & Railways transport & Chromium, PAHs, mineral oils, asbestos \\
\hline 9400 & Research and development & Chromium, bischloromethyl, asbestos, solvents, ionising radiation \\
\hline 9500 & Medical or health services & Chromium, PAHs, arsenic, nickel, ionising radiation \\
\hline
\end{tabular}

PAHs=polycyclic aromatic hydrocarbons.

consumption was expressed as number of pack-years. One pack-year corresponds to the smoking of one packet of 25 cigarettes a day for 1 year. Smoking of cigarillos, cigars, and a pipe was converted to smoking of cigarettes according to the number of grams of tobacco. The resulting number of pack-years for cigarillos, cigars, and pipe has been multiplied by a factor $0.9,0.9$, and 0.6 , respectively, to adjust for a lower relative risk of lung cancer of these smoking categories. ${ }^{20}$

DATA ANALYSIS

To allow for an induction latency period before diagnosis of the disease, a time lag of 10 years was applied to all exposure variables, including smoking history, occupations, and self reported occupational exposures.

Associations between lung cancer and occupations or exposures to specific carcinogens were estimated by odds ratios (ORs) with multiple logistic regression analysis. Case-control status was the dependent variable, and occupations, exposure to carcinogens, and potentially confounding variables were the independent variables. The associations between the poten-

Table 2 Population characteristics of cases and controls, by numbers (\%), unless indicated otherwise, risks of having lung cancer, $O R=1$ as reference category

\begin{tabular}{llll}
\hline Characteristic & $\begin{array}{l}\text { Cases } \\
(n=478)\end{array}$ & $\begin{array}{l}\text { Controls } \\
(n=536)\end{array}$ & Adjusted OR (95\% CI) \\
\hline $\begin{array}{l}\text { Age mean (SEM) (y) } \\
\text { Smoking category: }\end{array}$ & $65(0.4)$ & $62(0.4)$ & $1.05(1.03$ to 1.07$)$ \\
$\quad$ Never & $7(1.5)$ & $93(17.4)$ & 1 \\
$\quad$ Ex & $92(19.2)$ & $176(32.8)$ & $4.2(1.8$ to 9.8$)$ \\
$\quad$ Current & $379(79.3)$ & $267(49.8)$ & $14.5(6.3$ to 33.4$)$ \\
Pack-years: & $34.7(1.1)$ & $22.6(1.0)$ & $1.01(1.00$ to 1.02$)$ \\
$\quad$ Mean (SEM) & 30.9 & 19.0 & \\
$\quad$ Median & $379(79.5)$ & $472(88.4)$ & 1 \\
Marital status: & $76(15.9)$ & $47(8.8)$ & $1.6(1.0$ to 2.4$)$ \\
$\quad$ Married & $22(4.6)$ & $15(2.8)$ & $2.2(0.9$ to 9.8$)$ \\
$\quad$ Divorced or widowed & & & \\
$\quad$ Single & $56(11.7)$ & $92(17.2)$ & 1 \\
Education: & $252(52.7)$ & $275(51.3)$ & $1.2(0.8$ to 1.8$)$ \\
$\quad$ High & $170(35.6)$ & $169(31.5)$ & $0.9(0.5$ to 1.4$)$ \\
$\quad$ Middle & & & \\
$\quad$ Low & $89(18.6)$ & $144(26.9)$ & 1 \\
Socioeconomic status: & $75(15.7)$ & $112(20.9)$ & $1.2(0.8$ to 1.7$)$ \\
$\quad$ High & $314(65.7)$ & $280(52.2)$ & $2.3(1.5$ to 3.4$)$ \\
$\quad$ Middle & &
\end{tabular}

tial confounders age, marital status, education level, socioeconomic status, smoking, and number of pack-years, and lung cancer were determined by entering them simultaneously into a logistic regression model. As a result, variables that seemed to be significantly associated with lung cancer were included as adjustment variables in the subsequent multiple regression models. For each job category subjects ever employed in that particular category were compared with all other subjects. Thus the OR of each category estimates the risk of lung cancer relative to the mean risk of all other categories. Subjects with exposure, self reported as well as derived from the job task exposure matrix, to each carcinogen were compared with subjects without exposure to any of the carcinogens under study. Thus, the resulting $\mathrm{OR}$ estimates the risk of lung cancer relative to the risk of subjects without exposure. Moreover, occupational exposures, significantly associated with lung cancer according to job task exposure matrix as ever versus never exposed, were examined relative to their duration of exposure. For each individual carcinogen exposure was categorised according to the tertiles of exposure duration among the exposed subjects; the reference category consisted of subjects without that particular exposure.

In univariate analyses test results of $p<0.05$ were considered significant; in multivariate analyses ORs were considered significant if the $95 \%$ confidence intervals (95\% CIs) did not include the value 1 . Statistical analyses were performed with SPSS-PC+ (SPSS, Chicago, Ill, USA) and EGRET (SERC, Seattle, WA, USA).

\section{Results}

The total study population consisted of 1014 subjects, 478 cases and 536 controls. Population characteristics and their association with lung cancer are shown in table 2. Cases were significantly older than controls (mean age 65 (SEM 0.4) and 62 (SEM 0.4), respectively). 
Table 3 Distribution of occupations and industries coded according to the industrial classification 1981 (Appendix D OPCS 1980) in cases and controls; risks of having lung cancer, adjusted for age, smoking history, cigarette consumption, civil and socioeconomic status

\begin{tabular}{llll}
\hline Industrial category & Cases & Controls & Adjusted OR (95\% CI) \\
\hline Agriculture, fishing & 48 & 64 & $0.7(0.4$ to 1.0$)$ \\
Mining, energy supply & 15 & 24 & $0.7(0.3$ to 1.4$)$ \\
Metal manufacturing & 24 & 36 & $0.6(0.3$ to 1.1$)$ \\
Non-metalic mineral production & 45 & 51 & $0.9(0.6$ to 1.4$)$ \\
Chemical industry & 22 & 33 & $0.7(0.4$ to 1.3$)$ \\
Manufacturing of metal goods & 66 & 45 & $1.6(1.0 \text { to } 2.5)^{\star}$ \\
Mechanical engineering & 34 & 40 & $1.0(0.6$ to 1.6$)$ \\
Electrical engineering & 32 & 45 & $0.9(0.6$ to 1.6$)$ \\
Manuf motor vehicles & 33 & 27 & $1.4(0.8$ to 2.5$)$ \\
Other transport equipment & 56 & 30 & $2.3(1.3 \text { to } 4.0)^{\star}$ \\
Textile, clothing, leather & 35 & 23 & $1.7(0.9$ to 3.1$)$ \\
Food, drink, tobacco & 63 & 58 & $1.1(0.7$ to 1.7$)$ \\
Timber or paper products & 60 & 62 & $1.0(0.6$ to 1.5$)$ \\
Rubber, plastic, other & 15 & 11 & $2.8(0.9$ to 8.4$)$ \\
Building or road construction & 75 & 110 & $0.6(0.4 \text { to } 0.9)^{\star}$ \\
Distribution, hotels, catering & 77 & 75 & $1.1(0.8$ to 1.6$)$ \\
Vehicle or goods repair & 46 & 38 & $1.5(0.9$ to 2.5$)$ \\
Transport on land, etc & 62 & 63 & $0.8(0.5$ to 1.2$)$ \\
Transport on sea or river & 20 & 24 & $0.9(0.5$ to 1.8$)$ \\
Transport support service & 84 & 59 & $1.6(1.1 \text { to } 2.4)^{\star}$ \\
Postal or telecom service & 12 & 16 & $0.9(0.4$ to 2.0$)$ \\
Banking, insurance, business & 24 & 50 & $0.6(0.4$ to 1.1$)$ \\
Public administration & 138 & 144 & $1.2(0.9$ to 1.6$)$ \\
Education, research, health & 30 & 39 & $1.2(0.7$ to 2.1$)$ \\
Cultural, domestic, personal services & 14 & 29 & $0.5(0.2 \text { to } 0.9)^{\star}$ \\
*p<0.05. & & &
\end{tabular}

Table 4 Associations between occupational exposure to potential carcinogens and lung cancer (unexposed subjects as reference group)

\begin{tabular}{|c|c|c|c|c|}
\hline \multirow[b]{2}{*}{ Carcinogen } & \multicolumn{2}{|c|}{ Self reported exposure } & \multicolumn{2}{|c|}{ fob task exposure } \\
\hline & $\begin{array}{l}\text { Cases/ } \\
\text { controls (n) }\end{array}$ & $\begin{array}{l}\text { Adjusted OR } \\
(95 \% \mathrm{CI})\end{array}$ & $\begin{array}{l}\text { Cases/ } \\
\text { controls (n) }\end{array}$ & $\begin{array}{l}\text { Adjusted OR } \\
(95 \% \text { CI) }\end{array}$ \\
\hline Unexposed (reference) & $180 / 209$ & 1 & $186 / 242$ & 1 \\
\hline Molybdenum & $21 / 13$ & $2.1(0.9$ to 5.1$)$ & $52 / 34$ & $2.1(1.2 \text { to } 3.7)^{\star}$ \\
\hline Mineral oils & $144 / 148$ & $1.1(0.7$ to 1.5$)$ & $80 / 61$ & $1.7(1.1 \text { to } 2.7)^{\star}$ \\
\hline Chromium & $53 / 52$ & $1.3(0.8$ to 2.1$)$ & $162 / 149$ & $1.4(1.0 \text { to } 1.9)^{\star}$ \\
\hline Wood dust & $65 / 63$ & $1.3(0.8$ to 2.0$)$ & $13 / 15$ & $1.5(0.9$ to 2.6$)$ \\
\hline Solvents & $135 / 132$ & $1.2(0.8$ to 1.7$)$ & $146 / 138$ & $1.3(0.9$ to 1.8$)$ \\
\hline PAHs & $77 / 78$ & $1.1(0.7$ to 1.7$)$ & $235 / 233$ & $1.2(0.9$ to 1.6$)$ \\
\hline Arsenic & $17 / 12$ & $2.1(0.9$ to 5.0$)$ & $134 / 130$ & $1.2(0.9$ to 1.8$)$ \\
\hline Nickel & $39 / 28$ & $1.4(0.7$ to 2.5$)$ & $120 / 117$ & $1.1(0.8$ to 1.6$)$ \\
\hline Bischloromethyl & $41 / 34$ & $1.5(0.8$ to 2.7$)$ & $44 / 38$ & $1.0(0.4$ to 2.5$)$ \\
\hline Lindane/pesticides & $57 / 80$ & $0.7(0.5$ to 1.2$)$ & $80 / 94$ & $1.0(0.7$ to 1.5$)$ \\
\hline Asbestos & $120 / 117$ & $1.2(0.8$ to 1.7$)$ & $161 / 169$ & $1.0(0.7$ to 1.4$)$ \\
\hline Vinylchloride & $46 / 44$ & $1.1(0.6$ to 2.0$)$ & $28 / 38$ & $0.8(0.4$ to 1.5$)$ \\
\hline
\end{tabular}

${ }^{\star} \mathrm{p}<0.05$.

$\mathrm{PAHs}=$ polycyclic aromatic hydrocarbons.

Table 5 Association between lung cancer and duration (tertiles) of occupational exposure to carcinogens (exposure according to job task)

\begin{tabular}{llll}
\hline Carcinogen & Duration $(y)$ & Cases/controls $(n)$ & OR $(95 \%$ CI) \\
\hline Molybdenum & 0 (reference) & $186 / 242$ & 1 \\
& 1 to 4 & $13 / 8$ & $1.6(0.6$ to 4.4$)$ \\
& 4 to 21 & $20 / 14$ & $1.8(0.8$ to 4.1$)$ \\
Mineral oils & $>21$ & $19 / 12$ & $3.3(1.3 \text { to } 8.3)^{\star}$ \\
& 0 (reference) & $186 / 242$ & 1 \\
& 1 to 10 & $30 / 16$ & $2.6(1.3 \text { to } 5.3)^{\star}$ \\
Chromium & 10 to 33 & $26 / 22$ & $1.3(0.7$ to 2.6$)$ \\
& $>33$ & $24 / 23$ & $1.5(0.8$ to 3.1$)$ \\
& 0 (reference) & $186 / 242$ & 1 \\
& 1 to 10 & $53 / 57$ & $1.3(0.8$ to 2.1$)$ \\
& 10 to 30 & $47 / 46$ & $1.1(0.7$ to 1.9$)$ \\
& $>30$ & $62 / 46$ & $1.7(1.0 \text { to } 2.8)^{\star}$ \\
\hline
\end{tabular}

${ }^{\star} \mathrm{p}<0.05$.

For each year of age the risk of lung cancer was estimated to increase by $5 \%$. Only $1.5 \%$ of cases were never-smokers, compared with $17 \%$ of controls. By contrast, almost $80 \%$ of the cases were current smokers, compared with $50 \%$ of controls. The risks of lung cancer for ex-smokers and current smokers were, respectively, 4 and 14 times higher than for never smokers. Cumulative tobacco consumption was also significantly higher among cases than among controls (median number of pack-years $30.9 v 19.0, \mathrm{p}<0.001)$. The adjusted $\mathrm{OR}$ for pack-years indicated that the risk of lung cancer increased by $1 \%$ for each additional pack-year. Cases were more likely to be divorced, widowed, or single than controls. Although cases more often had a low level of education than controls, the association between lower education and lung cancer did not reach significance when adjusted for other population characteristics. Finally, low socioeconomic status was significantly associated with lung cancer, independently from smoking, marital status, and education level.

In table 3 the distributions among cases and controls of occupational categories, according to the division headings of the OPCS industrial classification 1981, are presented along with their associations with lung cancer. Job categories with less than 10 cases or controls were not included in the table. Subjects can occur in more than one category. Workers in the categories manufacturing of metal goods, manufacturing of transport equipment (other than automobiles) and transport support services showed significantly increased risks of lung cancer, whereas workers in construction of building or roads and in cultural, domestic, and personal services had significantly decreased risks of lung cancer.

Self reported occupational exposure to molybdenum and arsenic showed associations of borderline significance (lower limit of 95\% $\mathrm{CI} \geqslant 0.9$ ) with the occurrence of lung cancer (table 4; substances with $<10$ cases or controls were not included in the table). When determined by job task exposure matrix, exposure to molybdenum (OR 2.1), mineral oils (OR 1.7), and chromium (OR 1.4) were significantly associated with lung cancer, whereas associations between lung cancer and exposure to solvents, PAHs, arsenic, and wood dust were of borderline significance only.

When analysed by duration of exposure, the associations of exposure to molybdenum and (to a lesser degree) chromium increased with increasing duration (table 5). In both exposures only those in the highest category (molybdenum $>21$ years, chromium $>30$ years) showed a significant relation with lung cancer. Exposure to mineral oils seemed to be significant only for workers with a duration between 1 and 10 years.

No confounding effect of smoking was found in the relation between occupational exposure and lung cancer. The distribution of smoking categories did not differ between subjects with and without exposure, among cases as well as among controls $\left(\chi^{2}\right.$ for trend, df $\left.1, \mathrm{p}>0.7\right)$, nor did the mean cumulative tobacco consumption (Mann-Whitney $U$ test, $\mathrm{p}>0.2$ ). Similar results were obtained when stratified for each individual exposure (results not shown).

\section{Discussion}

In the present study we found a significantly increased risk of lung cancer among workers employed in manufacturing of metal goods, of 
transport equipment (other than automobiles) and in transport supporting services. Furthermore, after linkage of specific job tasks with potential exposure to carcinogens, a significantly increased risk of lung cancer was found among workers exposed to chromium, molybdenum, and mineral oils. These associations were independent of smoking, tobacco consumption, or socioeconomic factors.

Comparisons of risks of lung cancer between occupational studies are not only limited by differences in method, but also by different prevalences of potential exposures. The occupational categories at risk in our study are a reflection of the types of industries settled in the study area. Job titles of workers in manufacturing of metal goods included forgemen, welders, and foundry workers. Manufacturing of non-automobile transport equipment mainly included workers in shipyards, whereas the transport support services category consisted of dockers, warehousemen, and storage men in particular. These findings confirm already well known or suspected occupations and job titles with an excess risk of lung cancer, including welders, metal workers, shipyard workers, and dock workers. ${ }^{6}{ }^{21-27}$ A significantly lower risk of lung cancer was found among workers in building or road construction (bricklayers, road surfacers, concreters) and among workers in the aggregated category of cultural (artists, writers), domestic (housekeepers, porters) and personal (hair dressers, launderers) services. The lower risk of lung cancer for workers in building and road construction contrasts with findings of other studies in which occupations related to construction usually have been associated with an increased risk of lung cancer. ${ }^{16}{ }^{28}$ This may be due to the classification system used, by which the job category construction consists of a single code only, causing all job titles to have the same code. This category contained 75 cases and 110 controls; however, exclusion of all subjects without an affirmative answer to one or more of the additional specific job task questions, decreased the number of controls to 89 , resulting in a crude OR for having lung cancer of 0.9 (95\% CI 0.7 to 1.3$)$. Thus, the classification system led to an overestimation of exposure among controls only.

We found significant excess risks of lung cancer among subjects exposed to chromium, mineral oils, and molybdenum. An increased risk, although of borderline significance, was also found in subjects exposed to polycyclic aromatic hydrocarbons, arsenic, solvents, and wood dust. These substances have often been reported as being lung carcinogens, ${ }^{129-31}$ with the exception of molybdenum. In two animal studies a significant increase was noted in the number of lung tumours in mice after giving them molybdenum trioxide, ${ }^{32} 33$ whereas, to our knowledge, the only assessment in humans could not find a significant association between exposure to molybdenum (molybdate orange pigment) and lung cancer. ${ }^{34}$ However, this was an indirect finding from a study designed to investigate exposure to chromate pigments and conducted in companies that also produced molybdate pigments. In our study occupational exposure to molybdenum was associated with lung cancer, both for self reported exposure (although not quite significant, probably due to low prevalence) and when assessed by job task exposure matrix. Moreover, this association was dose related. The job task most often related to exposure to molybdenum was processing of stainless steel in the job category manufacturing of metal goods.

In general, in occupational studies the assessment of exposure remains difficult, as usually no exposure data are available from the work sites of the subjects. Exposure assessment is usually retrospective, and therefore susceptible to recall or information bias and subsequently misclassification.

If accuracy on past exposures is less affected in cases than in controls-for example, due to recall bias-misclassification will be differential, leading to overestimated associations. This would most likely apply for exposure to asbestos, because it is the most commonly known substance related to lung cancer. As we did not find a significant association between self reported exposure to asbestos and lung cancer, we conclude that misclassification is most likely to be unrelated to disease and therefore non-differential, leading to an underestimation of associations between lung cancer and exposure. This may explain the absence of significance of self reported exposures in our study, as self reported exposure in particular may be susceptible to recall or information bias.

To overcome this weakness in the assessment of exposure, job exposure matrices have been developed, in which each occupation (job title or job category) is linked to exposure to potential carcinogens. However, a general job exposure matrix, covering a wide range of occupations, is still sensitive to misclassification. ${ }^{14}{ }^{15}$ Its accuracy depends on the characteristics of the classification system by which occupations are coded. Detailed classification leads to many subdivisions containing only few subjects, resulting in unstable exposure estimates. Aggregation of job titles into larger categories causes loss of information on occupational data, resulting in inaccurate exposure estimates. These difficulties can largely be avoided by the use of a job task exposure matrix, in which different job tasks instead of job titles are listed on the occupation axis. Thus different exposures can be distinguished within each job title category, reducing the chance of misclassification of the exposure due to variability of exposure within a job category. ${ }^{1635}$ Another advantage of this method is that subjects are not asked directly for exposure to carcinogens, making a possible differential misclassification due to recall or information bias less likely.

Information on job tasks can be obtained by job specific additional questionnaires. The comprehensiveness of this information may be limited by the initial choice of job categories being at risk of lung cancer, on which the additional questionnaires are founded. For instance, in our study the job category transport support services, which subsequently seemed 
to be associated with a significant excess risk on lung cancer, was not accompanied by an additional job specific questionnaire. This may have resulted in an underestimation of the relations between several carcinogens and lung cancer.

Another potential source of bias may be the choice of controls. In our study controls consisted largely of patients with cardiovascular diseases, usually coronary atherosclerosis. The main reason for this choice was the independence of these disorders from the exposures under study. Still, this choice may have caused some bias through overrepresentation of certain occupations related to cardiovascular disease that generally are associated with low levels of exposure to carcinogens. This may have led to an overestimation of the observed associations. However, given the relatively low number of subjects in these occupations-for example, in the category banking, business - and given the adjustment for socioeconomic status in the regression analyses, thereby indirectly controlling for differences in job related social classes, the effect on the observed associations will be insignificant.

In conclusion, the current study has shown a significant excess risk of lung cancer among workers in the job categories manufacturing of metal goods, manufacturing of transport equipment (other than automobiles) and transport support services. These risks were independent of smoking, cumulative tobacco consumption, education, civil status, and economic status. Assessment of exposure to specific carcinogens by using a job task exposure matrix resulted in significant associations of chromium, mineral oils, and molybdenum with lung cancer. This is, to our knowledge, the first occupational study reporting a significant association between exposure to molybdenum and lung cancer.

We thank Dr AM Bonroy (Intermedicale, Occupational Health Service, Antwerp), Dr Galdermans (Middelheim General Hospital, Antwerp), Dr Verresen (St Augustinus General Hospital, Antwerp), and Dr Mareels (Stuivenberg General Hospital, Antwerp) for their contributions to the organisation and realisation of the study, P Cartier, D Rondia, and M Muller (University of Liège, Belgium) for the construction of the job task exposure matrix, and $C$ Vrancken, $T$ de Winter, J Vleminckx, and $H$ Hammarberg (University of Antwerp) for the data collection. This study was supported by Grant No G 3008.93 of the Fund of Scientific Research of Flanders and by the Ministry of Health of Flanders.

1 Black RJ, Bray F, Ferlay J, et al. Cancer incidence and mortality in the European Union: cancer registry data and estimates of national incidence for 1990 . Eur 7 Cancer 1997;33:1057-107.

2 Doll R, Peto R. The causes of cancer: quantitative estimates of avoidable risks of cancer in the United States today. $f$ Natl Cancer Inst 1981;66:1191-308.

3 Pastorino U, Berrino F, Gervasio A, et al. Proportion of lung cancers due to occupational exposure. Int $\mathcal{f}$ Cancer cancers due $1984 ; 33: 231-7$.

4 Morabia A, Markowita S, Garibaldi K, et al. Lung cancer and occupation: results of a multicentre case-control study. Br f Ind Med 1992;49:721-7.

5 Lerchen ML, Wiggins CL, Samet J. Lung cancer and occupation in New Mexico. $\mathcal{F}$ Natl Cancer Inst 1987;79:639-45.
6 Vineis P, Thomas T, Hayes RS, et al. Proportion of lung cancers in males, due to occupation, in different areas of the USA. Int 7 Cancer 1988; $42: 851-6$.

7 Ronco G, Ciccone G, Mirabelli D, et al. Occupation and lung cancer in two industrialized areas of Northern Italy. Int $\mathcal{F}$ Cancer 1988;41:354-8.

8 Damber LA, Larsson LG. Occupation and male lung cancer: a case-control study in Northern Sweden. Br f Ind Med 1987;44:446-53.

9 Dubrow R, Wegman DH. Setting priorities for occupational cancer research and control: synthesis of the results of occupational disease surveillance studies. $\mathcal{F}$ Natl Cancer Inst 1983;71:1123-42.

10 International Agency for Research on Cancer. Monographs on the evaluation of carcinogenic risk of chemicals to humans. Vols 1-26. Lyon: IARC, 1972-1981.

11 International Agency for Research on Cancer. Chemicals, industrial processes and industries associated with cancer in humans. IARC Monograph on the evaluation of the carcinogenic risk of chemicals in humans; suppl 4. Lyon: IARC, 1982 .

12 Steenland K, Loomis D, Shy C, et al. Review of occupational lung carcinogens. Am f Ind Med 1996;29:474-90.

13 Hoar SK, Morrison AS, Cole P, et al. An occupation and exposure linkage system for the study of occupational carcinogenesis. Occup Med 1980;22:722-6.

14 Pannett B, Coggon D, Acheson ED. A job-exposure matrix for use in population based studies in England and Wales. Br f Ind Med 1985;42:777-83.

15 Olsen J. Limitations in the use of job exposure matrices. Scand F Soc Med 1988;4:205-8.

16 Jockel KH, Ahrens W, Wichmann HE, et al. Occupational and environmental hazards associated with lung cancer. Int f Epidemiol 1992;21:202-13.

17 Stewart PA, Stewart WF. Occupational case-control studies: II. Recommendations for exposure assessment. Am $\mathcal{F}$ Ind Med 1994;26:313-26.

18 Bartsch P, Rondia D. Recherche épidémiologique sur l'origine professionnelle des cancers primaires des bronches. Rapport final. Liège: University of Liège, 1995.

19 Classification of Occupations and coding index. Office of Population Censuses and Surveys. London: The Stationery Office, 1981.

20 Lange P, Nyboe J, Appleyard M, et al. Relationship of the type of tobacco and inhalation pattern to pulmonary and total mortality. Eur Respir F 1992;5:1111-7.

21 Gustafsson L, Wall S, Larsson LG, et al. Mortality and cancer incidence among Swedish dock workers-a retrospec6.

22 Schoenberg JB, Stemhagen A, Mason ThJ, et al. Occupation and lung cancer risk among New Jersey white males. $\mathcal{F}$ Natl Cancer Inst 1987;79:13-21.

23 Blot WJ, Harrington JM, Toledo A, et al. Lung cancer after employment in shipyards during world war II. $N$ Engl $\mathcal{F}$ Med 1978;299:620-4.

24 Lynge E, Kurppa K, Kristofersen L, et al. Silica dust and lung cancer: results from the Nordic occupational mortality and cancer incidence registers. F Natl Cancer Inst 1986;77: 883-9.

25 Sanden A, Naslung P, Jarvholm B. Mortality in lung and gastro-intestinal cancer among shipyard workers. Int Arch Occup Environ Health 1985;55:277-83.

26 Emmelin A, Nystrom L, Wall S. Diesel exhaust exposure and smoking: a case-referent study of lung cancer among Swedish dock workers. Epidemiology 1993;4:237-44.

27 Coggon D, Pannet B, Osmond C, et al. A survey of cancer and occupations in young and middle aged men. I. Cancers of the respiratory tract. Br f Ind Med 1986;43:332-8.

28 Partanen T, Boffetta P. Cancer risk in asphalt workers and roofers: review and meta-analysis of epidemiologic studies. roofers: review and meta-analysis

29 Ruder AM. Epidemiology of occupational carcinogens and mutagens. Occup Med 1996;11:487-512.

30 Ward E. Overview of preventable industrial causes of occupational cancer. Environ Health Perspect 1995;103(suppl 8):197-203

31 Simonato L, Fletcher AC, Andersen A, et al. A historical prospective study of European stainless steel, mild steel and shipyard welders. Br f Ind Med 1991;48:145-54.

32 Stoner GD, Shimkin MB, Troxell MC, et al. Test for carcinogenicity of metallic compounds by the pulmonary tumor response in strain A mice. Cancer Res 1976;36:1744-7.

33 Shimkin MB, Stoner GD, Theiss JC. Lung tumour response in mice to metals and metal salts. Adv Exp Med Biol 1977; 91:85-91.

34 Kano K, Horikawa M, Utsunomiya T, et al. Lung cancer mortality among a cohort of male chromate pigment workers in Japan. Int 7 Epidemiol 1993;22:16-22.

35 Rona RJ, Taub NA, Rasmussen S. Case-control studies in cancer patients as a surveillance system of occupational exposure in the European Community. $\mathcal{F}$ Epidemiol Community Health 1993;47:320-5. 